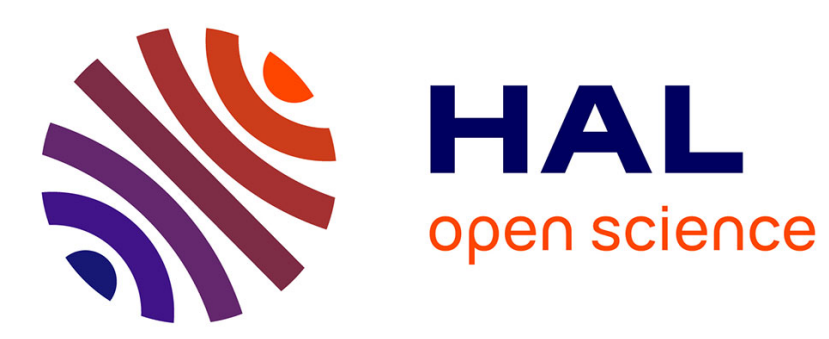

\title{
Reflectivity and electronic structures of Ni-silicides
}

\author{
A. Humbert, A. Cros
}

\section{To cite this version:}

A. Humbert, A. Cros. Reflectivity and electronic structures of Ni-silicides. Journal de Physique Lettres, 1983, 44 (23), pp.929-933. 10.1051/jphyslet:019830044023092900 . jpa-00232284

\section{HAL Id: jpa-00232284 https://hal.science/jpa-00232284}

Submitted on 1 Jan 1983

HAL is a multi-disciplinary open access archive for the deposit and dissemination of scientific research documents, whether they are published or not. The documents may come from teaching and research institutions in France or abroad, or from public or private research centers.
L'archive ouverte pluridisciplinaire HAL, est destinée au dépôt et à la diffusion de documents scientifiques de niveau recherche, publiés ou non, émanant des établissements d'enseignement et de recherche français ou étrangers, des laboratoires publics ou privés. 
Classification

Physics Abstracts

$78.65-71.20$

\title{
Reflectivity and electronic structures of Ni-silicides
}

\author{
A. Humbert and A. Cros \\ Faculté des Sciences de Luminy, Département de Physique (*), Case 901, \\ 13288 Marseille Cedex 9, France
}

(Reçu le 4 juillet 1983, accepté le 13 octobre 1983)

\begin{abstract}
Résumé. - Nous présentons une étude comparative de la réflectivité du nickel et de ses siliciures $\left(\mathrm{Ni}_{4} \mathrm{Si}, \mathrm{Ni}_{2} \mathrm{Si}, \mathrm{NiSi}\right.$ et $\left.\mathrm{NiSi}_{2}\right)$ dans le domaine visible et proche infra-rouge. Une interprétation des structures observées est obtenue par comparaison avec les densités d'états de bande de valence mesurées par photoémission $\mathrm{X}$ et les calculs de structure de bande publiés.

Abstract. - A comparative study of the visible and near infra-red reflectivity of nickel and its silicides $\left(\mathrm{Ni}_{4} \mathrm{Si}, \mathrm{Ni}_{2} \mathrm{Si}, \mathrm{NiSi}\right.$ and $\left.\mathrm{NiSi}_{2}\right)$ is presented. The observed structures are interpreted by comparison with valence band density of states measured by $\mathrm{X}$-ray photoemission and published band structure calculations.
\end{abstract}

Metal silicides have interesting applications in devices technologies [1]. Considerable impetus to the field has been provided by the successful application of modern thin film vapour deposition techniques to produce layers of very high physical and structural integrity. It is now well established from U.V. photoemission measurements and theoretical calculations that the formation of these compounds has a direct effect on the valence band densities of states [2, 3]. These modifications are expected to induce strong changes in the reflectivity behaviour of these materials. To our knowledge, their optical properties have not been investigated and it is the purpose of this letter to discuss them in the particular case of nickel. An interesting point is that the metal silicides have well defined stoichiometry and crystallography, so that the influence of Si incorporation in the metal matrix can be precisely monitored. Moreover the increased applications of silicidesilicon Schottky diodes in infra-red imaging requires a good knowledge of the optical properties.

Samples of $\mathrm{Ni}_{2} \mathrm{Si}, \mathrm{NiSi}$ and $\mathrm{NiSi}_{2}$ have been prepared by thermal annealing at respectively $200^{\circ} \mathrm{C}, 400^{\circ} \mathrm{C}$ and $700^{\circ} \mathrm{C}$ of thin $(\sim 1000 \AA) \mathrm{Ni}$ film deposited on a Si (100) wafer. $\mathrm{Ni}_{4} \mathrm{Si}$ has been co-evaporated on an oxidized Si wafer. Rutherford backscattering and X-ray diffraction characterization have shown that the films are fully reacted and that only one silicide phase with its characteristic crystallographic structure is present in each sample. This peculiarity is a general phenomenon in thin film growth which has been precisely established previously [4].

$\mathrm{X}$-ray photoemission has been performed using the monochromated $\mathrm{Al}(\mathrm{K} \alpha)$ line at $1486 \mathrm{eV}$

(*) ERA CNRS 373. 
with a resolution of $1 \mathrm{eV}$. Reflectivity spectra have been taken at near normal incidence with a parallel light beam in the $0.6-4 \mathrm{eV}$ spectral range. For the optical measurements the samples have been $n_{4}$ exposed to air. This results in the formation of a superficial $\mathrm{SiO}_{2}$ layer $(20-40 \AA)$ which has been studied previously [5]. The important point is that this layer acts as a passivating film which prevents any subsequent impurity diffusion in the bulk of the silicides. Such a film is transparent in the spectral range investigated and its influence is also minimized by near normal incidence measurements. Surface roughness can also affect optical spectra. We have verified by scanning electron microscopy that all samples are flat except $\mathrm{NiSi}_{2}$ which presents some surface roughness on a $1000 \AA$ lateral scale.

The different reflectivity spectra are shown in figure 1 . The nickel curve has been recorded on a $1700 \AA$ thick polycrystalline film evaporated on $\mathrm{a} \mathrm{SiO}_{2}$ substrate. Its shape is in agreement with what has already been published [6]. One notices a slow decrease of the reflectivity. The absence of a sharp cut off associated to a plasma resonance is due to the presence of interband transitions. In $\mathrm{Ni}$ the Fermi level intersects the $\mathrm{d}$ bands and the onset of interband transitions is about $0.3 \mathrm{eV}$. We will distinguish two categories of silicides depending on the shape of the reflectivity. The first one corresponds to what can be called metal rich compounds $\left(\mathrm{Ni}_{4} \mathrm{Si}, \mathrm{Ni}_{2} \mathrm{Si}\right)$. They are characterized by reflectivity curves similar to the Ni one, except for a decrease of its absolute intensity with decreasing $\mathrm{Ni}$ concentration. A completely different behaviour is observed for $\mathrm{NiSi}$ and $\mathrm{NiSi}_{2}$. Well defined structures appear at $2 \mathrm{eV}$ for $\mathrm{NiSi}$ and $3.1 \mathrm{eV}$ for $\mathrm{NiSi}_{2}$. A weaker bump is also observed at $2 \mathrm{eV}$ for $\mathrm{NiSi}_{2}$. Simultaneously a sharp drop of the reflectance is seen around $1 \mathrm{eV}$. Finally we also present on the same figure the well known spectrum of crystalline silicon for comparison.

Our interpretation of these spectra is based on the examination of the valence band densities of states obtained by X-ray photoemission (Fig. 2). It is worth noticing that the same distinction between metal rich and silicon rich silicides can be made. All spectra are dominated by the emission from the $\mathrm{Ni} 3 \mathrm{~d}$-derived electronic states. For $\mathrm{Ni}_{4} \mathrm{Si}$ and $\mathrm{Ni}_{2} \mathrm{Si}$, this one is slightly modified when compared to pure Ni. The maximum of the $3 \mathrm{~d}$ density of states is weakly shifted $(0.1 \mathrm{eV}$ for $\mathrm{Ni}_{4} \mathrm{Si}, 0.6 \mathrm{eV}$ for $\mathrm{Ni}_{2} \mathrm{Si}$ ) towards higher binding energies but the Fermi level still intersects the $\mathrm{d}$ band. In contrast, the shift is more pronounced for $\mathrm{NiSi}$ and $\mathrm{NiSi}_{2}(1.1 \mathrm{eV}$ and $2.1 \mathrm{eV}$ respectively). The densities of states at the Fermi level are strongly reduced but these compounds are still metallic [1]. These tendencies are in agreement with calculated densities of states [3] which suggest hybridization between silicon $p$ and nickel $d$ orbitals. This induces the creation of bonding and antibonding states and the net result is a displacement of the derived states to higher binding energy.

A complete interpretation of optical structures supposes the comparison between the experimental optical absorption and the joint density of states deduced from the band structure. In our case the limited spectral range of the reflectivity makes a Kramers Krönig analysis quite speculative. Moreover band structure calculations are not available for these compounds except for $\mathrm{NiSi}_{2}$. Nevertheless the comparison between X-ray photoemission (Fig. 2) and U.V. photoemission spectra $[2,3]$ clearly shows that the main structures are associated to strong valence band $\mathrm{Ni}-\mathrm{d}$ derived structures $\left(2 \mathrm{eV}\right.$ for $\mathrm{NiSi}$ and $3.1 \mathrm{eV}$ for $\left.\mathrm{NiSi}_{2}\right)$, and that final state effects are negligible. From the good agreement between the energy positions of these maxima and the observed reflectivity structures, we suggest that the latter are associated to interband transitions from these $d$ derived states to the Fermi level. The presence of a flat Ni-d derived band about $3 \mathrm{eV}$ below the Fermi level in the band structure calculation of $\mathrm{NiSi}_{2}$ reinforces this analysis [2].

Simultaneously one notices the appearance of a sharp reflectivity cut-off in the near infra-red for the $\mathrm{Si}$ rich silicides. For these compounds the d derived states are well below $E_{\mathrm{F}}$ and the electronic states at the Fermi level are mainly due to Si hybridized levels as suggested by theoretical calculations [2,3]. This means that $\mathrm{Si}$ atoms may be considered as " metallic » in the sense that they contribute to electronic levels at $E_{\mathrm{F}}$. We must emphasize that this point has been 


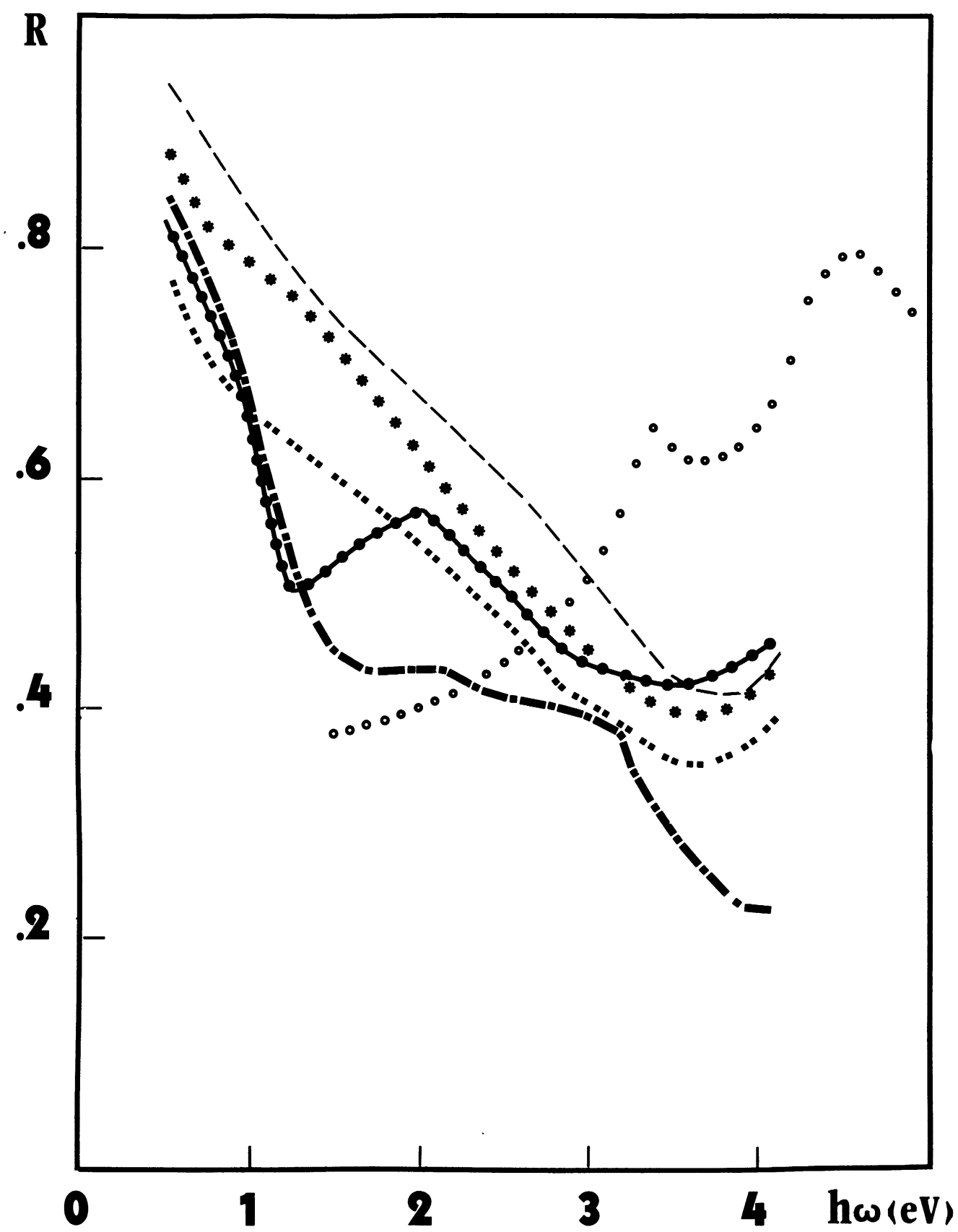

Fig. 1. - Normal incidence reflectivity $R$ of $\mathrm{Ni}$, Si and Ni-silicides, $\left(--\mathrm{Ni} ; * \mathrm{Ni}_{4} \mathrm{Si} ; \boldsymbol{\square} \boldsymbol{\square} \mathrm{Ni}_{2} \mathrm{Si} ; \bullet \rightarrow\right.$ $\mathrm{NiSi} ;$ - $\left.\mathrm{NiSi}_{2}\right)$. Silicon data are taken from reference 8 for comparison $(0 \circ \bullet)$.

confirmed experimentally by measurements of the spin lattice relaxation times $\mathrm{T}$ of ${ }^{29} \mathrm{Si}$ in the silicides [7]. These studies have shown that $T$ is characteristic of a metal and that $\mathrm{Si}$ is more " metallic » in Si rich silicides. Considering the reflectivity data (Fig. 1) of these compounds, those free electrons are probably associated to the sharp cut-off observed at about $1 \mathrm{eV}$ for NiSi 


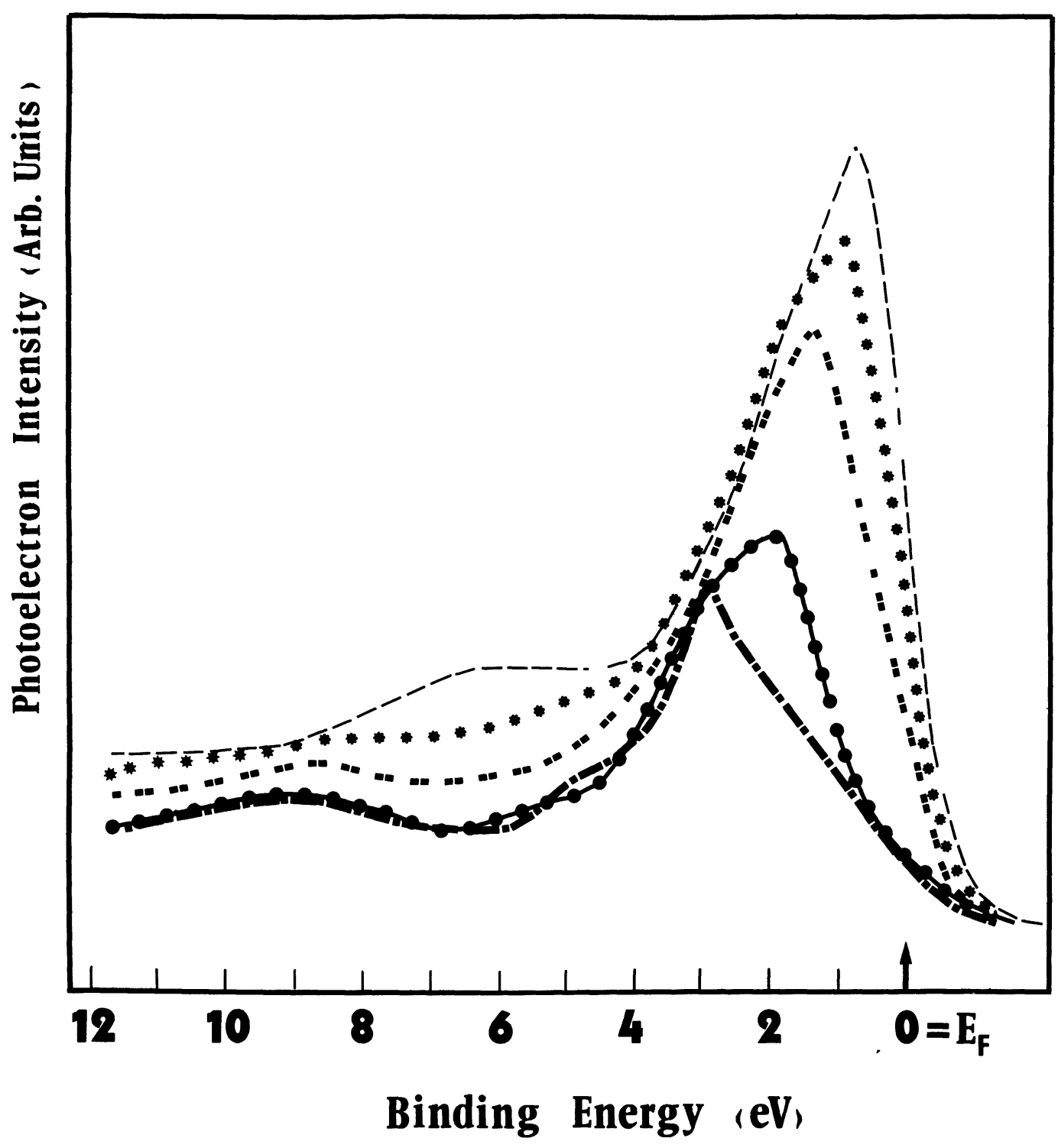

Fig. 2. - X-ray photoemission spectra from the same samples used for the reflectivity measurements of

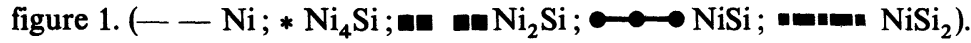

and $\mathrm{NiSi}_{2}$. In contrast, for $\mathrm{Ni}$ rich silicides, $E_{\mathrm{F}}$ intersects the onset of the Ni-d derived band and the electronic states at $E_{\mathrm{F}}$ originate simultaneously from the Ni-d states and the Si hybridized levels, in agreement with theoretical calculations $[2,3]$. This explains qualitatively the absence of reflectivity structures and the continuous decrease of the reflectivity as it is the case for pure Ni.

To briefly conclude this letter, we can say that the addition of silicon to nickel in the form of well defined compounds has interesting consequences on the reflectivity spectra. Two different classes of silicides have been distinguished, according to whether they are $\mathrm{Ni}$ rich $\left(\mathrm{Ni}_{4} \mathrm{Si}_{-} \mathrm{Ni}_{2} \mathrm{Si}\right)$ or Si rich ( $\left.\mathrm{NiSi}-\mathrm{NiSi}_{2}\right)$. In the first case, the reflectivity is qualitatively similar to what is found for $\mathrm{Ni}$, while in the second case there appears well defined structures and a sharper near infra-red 
cut-off. Our analysis based on measured valence band densities of states and existing theoretical calculations has assigned these structures to transition from $\mathrm{Ni}-\mathrm{d}$ derived levels to the Fermi level. We have also suggested that the near infra-red cut-off is associated to the peculiar metallic properties of $\mathrm{Si}$ atoms in these compounds.

\section{References}

[1] See for example : Thin film interdiffusion and reactions, edited by POATE, J. M., TU, K. N. and MAYER, J. M. (Wiley Interscience) 1978.

[2] Chabal, Y. J., Hamann, D. R., Rowe, J. E. and Schlüter, M., Phys. Rev. B 25 (12) (1982) 7598.

[3] Franciosi, A., Weaver, J. H., Schmidt, F. A., Phys. Rev. B 26 (2) (1982) 546.

[4] Tu, K. N., Ottaviani, G., Göselle, U. and Föll, H., J. Appl. Physics 54 (2) (1983) 758.

[5] Cros, A., Pollak, R. and Tu, K. N., Material Society Annual Meeting, Boston 1982, to be published.

[6] Ehrenreich, H. and Philipp, H. R., Phys. Rev. 128 (1962) 1622.

[7] Iwami, M., OKuno, K., Kamei, S., Ito, T. and Hiraki, A., J. Electrochem. Soc. (1980) 1542.

[8] Aspnes, D. E., Studna, A. A., Phys. Rev. B 27 (1983) 985. 